\title{
Façade Refurbishment of Existing Office Buildings: Do Conventional Energy-saving Interventions Always Work?
}

\begin{abstract}
Offices account for $40 \%$ of energy use in construction sector. Office building stock is already under-performing and dilapidating at a fast pace. With the current rate of replacing old building stock in the UK, it is expected that at least $60 \%$ of what was built before 1985 still exists in 2050 . Therefore, refurbishment, with an aim to improve performance of buildings, seems to remain as the most feasible and arguably most cost efficient way forward. Precedent studies in this area are not few and far between. However, some recommendations and interventions seems to have been taken for granted and thought to be globally applicable almost everywhere. This study chooses a recently refurbished office building to challenge this common belief. It was shown that, from the carbon point of view, benefits as a result of interventions were marginal. It was found that a full pre-refurbishment survey, measures aimed at reducing the performance gap between intended and actual figures, and study of occupancy patterns would probably help in this respect. The study results also showed that study of contextual conditions i.e. careful considerations with regards to building orientation, topography, site constraints, and exposure to solar gains will help achieve better results. Finally it was envisaged that better user engagement, communication and using few other measures to enhance user satisfaction will help guarantee some other aspects pertaining to performance than its mere energy consumption or carbon footprint.
\end{abstract}

Keywords: façade refurbishment; sustainable retrofit; office refurbishment; office buildings; building energy simulation; building performance.

\section{Introduction}

The construction sector represents one of the major contributors to the depletion of finite natural resources across the planet [1-3]. In the UK, buildings account for about 40$50 \%$ of all energy consumption and greenhouse gases (GHG) emissions [4-6]. In cities like London, this figure can rise up to $61 \%$, which is substantially higher than the average in the EU (41\%) and the US (36\%) [7]. More specifically, non-domestic buildings tend to have greater energy consumption per $\mathrm{m}^{2}$ of floor area compared to dwellings. Among non- 
domestic building typologies, offices are one of the major energy consumers [8], accounting for around $40 \%$ of the total consumption in the sector [4]. More than $75 \%$ of the UK nondomestic building stock was built before 1985, and about $60 \%$ of it will still exist in 2050 [9]. In fact, whilst $1-2 \%$ of the building stock is newly built each year, the rest is already out there and needs improvement [10]. More specifically in terms of the age of the office building stock, about $80 \%$ of the office floor spaces, in all regions of the UK, were built before 1990 [11], with U-values double, if not triple the current levels. Such poor thermal performances, along with the high-density occupancy profile, and the significant internal heat gains due to lighting, appliances and IT equipment, make existing offices one of the most energy intensive building types. In actual fact, they nearly double the sector average for heating, cooling, and ventilation [12]. In terms of $\mathrm{CO}_{2}$ emissions, offices account for more than $20 \%$ of the national figure but there is the technical potential to cut their emissions by up to $80 \%$, implementing solutions which are already available today [9].

In this context, existing office building stock offers a great opportunity for cutting back on greenhouse gas (GHG) emissions and energy consumption [13] and for reducing the negative impact of the construction sector on the environment [14]. Furthermore, those buildings are at the centre of everyday life in the urban fabric hence, if suffering from scarce thermal performance, they could have significant negative impact on economic, social and cultural aspects of their users' lives [8], making the sustained and continuous operation of the existing building stock a "much bigger but less focused question" than new construction [8].

Given façade's role as a physical barrier between the indoor and outdoor environments, interventions aimed at improving its performance are considered as one of the most effective ways to reduce energy consumption of buildings [15] and to enhance their indoor environmental quality [16]. In the continental climate of the UK, additional thermal insulation, replacement of existing windows with high performance glazing systems 
combined with thermal break frames, and installation of shading devices to reduce cooling loads, are all considered effective refurbishment interventions - just to name a few $[17,18]$. This research aims at investigating whether and to what extent such a common belief about façade improvements holds true regardless of the context. In doing so, a case study has been selected, simulated and assessed.

The paper starts with a critical review of literature to gauge how façade refurbishment can help improve energy performance in office buildings and how effective such interventions can potentially be. The design research and methodology will follow next to explain how it was tailored to suit the specific target of this research. This leads into the data collection strategies followed by the data analysis. The findings of the selected case study, an office building in south-east England which has recently gone through a major façade refurbishment with an aim to improve its energy performance, will then be discussed and triangulated with the previous work. This will be concluded to show how what seems to have been common expectation in such projects might not prove to be so if some preliminaries are not fully taken account for or if some aspects of the process involved are overlooked. Finally we will provide some suggestions for further research.

\section{Literature Review}

The Carbon Trust [17] states that "the existing [UK] building stock remains largely untouched and many refurbishment projects miss the opportunities to reduce emissions and deliver low carbon buildings". Recently, it is becoming clearer that reducing energy demand through retrofitting buildings deserves to become a priority [19]. Also European regulations see renovations of buildings as a must-take opportunity to enhance energy performance and reduce operational energy consumption [20]. In countries where fossils fuels still dominate, including the UK, operational energy - through its related GHG emissions - is deemed as a major contributor to Global Warming Potential (GWP) [21]. In this respect, innovations in 
non-domestic buildings in the UK have been estimated to be able to save up to $86 \mathrm{MtCO}_{2}$ by 2050 [22], which is more than $10 \%$ of the reduction needed to achieve the 2050 Climate Change Act target [23].

Significant opportunities to deliver such energy-efficient and low-carbon refurbishment undoubtedly lay within improvements to the building envelope [17]. Additional thermal insulation, installation of high-performance glazing systems, and passive measures such as natural ventilation, shading systems, and the use of daylighting are all beneficial interventions in that respect [18]. Some authors suggest that an improved insulation is more important than an increased solar control in existing, poorly insulated office building [12]. There are, however, counter-arguments which suggest traditional means of improving façade thermal performances are likely to increase cooling loads during warm/hot seasons [24].

The upgrade from standard single or double glazing to high efficiency double glazing to reduce heating loads has been considered as the most effective way to reduce the negative environmental impacts as a result of poor performance of old façade components [14]. Reduction in space heating in some investigated cases have been recorded to be as high as $35.5 \%$ [14]. Similarly, optimisation in envelope retrofit strategies involving the improvement of both transparent and opaque areas of the façade have been analysed and showed reduction of annual energy consumption by $15 \%$ and a decrease in annual $\mathrm{CO}_{2}$ emissions by $20 \%$ [25].

Different retrofitting strategies have also been investigated for different types of office buildings in different climatic regions $[24,26]$. Amongst those strategies, many relate to elements of the building façade such as the improvement of wall insulation, the replacement of windows and window frames, the use of shading devices, and the maximum deployment of natural ventilation. Such interventions resulted in significant energy reductions for all the office types in all the climatic regions, with values ranging from $20 \%$ up 
to more than $50 \%[24,26]$. Beneficial effects due to façade improvements, related to heating/cooling loads reduction, natural ventilation, and appropriate shading are also echoed by Wong et al. [27] and Jin and Overend [28].

Improved retrofitted fabrics have been also investigated in future scenarios from a climate change perspective [29]. The improved retrofitted fabric can achieve an impressive $61 \%$ reduction in terms of $\mathrm{CO}_{2}$ emissions related to heating, cooling, and ventilation [29].

Finally, when analysed from a life cycle perspective, interventions related to the building envelope have shown capable, in some cases, of reducing life cycle primary energy consumption of up to $53 \%$ [30]. To summarise, three main conclusions related to façade refurbishments can be drawn from the studies reviewed:

- Great energy reduction is achievable

- Significant carbon emissions can be saved

- Interventions beneficial in one season may have counter effects in other seasons

This paper will aim to verify whether those generally accepted hypotheses hold true in the selected case study whose full details are introduced in the next section.

\section{Research Design and Methodology}

This research utilises a single-case study research methodology with multiple-unit of analysis to investigate a recent sustainable refurbishment project. A case study is an intensive investigation of a phenomenon in its natural setting, and often makes use of a variety of data sources [31]. It is based on a constructivist paradigm [32]. Yin [33] strengthens the methodological legitimacy of case studies by arguing that a "fatal flaw in doing case studies is to conceive of statistical generalisation as the method of generalising the results of the case study" because cases are not sampling units and should be treated as experiments [34]. The primary strength of case study research is its reliance on data enquiry from different sources 
and multiple data collection techniques. This increases the validity of findings [35] hence the approach of this research; where a multitude of other methods - building energy and fabric surveys, energy simulation using an industry standard simulation software package, energy and carbon assessment and comparison against available benchmarks - have been employed to enrich and deepen the findings, increase its construct validity, internal validity, external validity and reliability [36].

The tool chosen for the Building Energy Simulation (BES) is IES VE (Virtual Environment), a powerful dynamic simulation software tool widely used by academics and practitioners alike. Among the main benefits of IES are its flexibility, a fairly user-friendly interface, and the possibility to address different aspects related to buildings without loss of accuracy and precision. In fact, the software tool is built around different sections that can eventually be interlinked to provide more accurate and reliable simulations. These include individual packages for solar shading calculation, ventilation analysis, thermal simulation, daylighting, etc. More importantly IES has been checked against guidelines and methodologies for Building Energy and Environmental Modelling (BEEM) software proving to be amongst the best software packages available [37]. Due to unavailability of better data, the nearest weather file was London which is, therefore, the one used. The building has been modelled with two scenarios: pre- and post-refurbishment. The need to opt for dynamic energy simulation over other methods, i.e. comparison of actual energy use pre- and postrefurbishment, is due to the peculiarity of the building which is jointly owned and occupied and combined and cumulative energy figures were not made available. However building owners allowed us to access and to survey the building for one entire day. Furthermore, they provided us with occupancy profiles and boilers settings. For the indoor environment survey we utilised a '4-in-1' environment monitor able to measure: 
- Temperature (resolution: $0.1^{\circ} \mathrm{C}$; accuracy: $\pm 3 \% \mathrm{rdg}$ in the range $-20.0^{\circ} \mathrm{C} \sim$ $\left.+200.0^{\circ} \mathrm{C}\right)$

- Relative Humidity (resolution: $0.1 \% \mathrm{RH}$; accuracy: $5 \% \mathrm{RH}$ at $25^{\circ} \mathrm{C}$ in the range $25 \% \sim 95 \% \mathrm{RH})$;

- Lighting level (resolution: $0.01 \mathrm{fc} / \mathrm{lux}$; accuracy: $\pm 5 \%$ rdg in the range $20-$ 20000 Lux);

- Sound level (resolution: $0.1 \mathrm{~dB}$; accuracy: $\pm 3.5 \mathrm{~dB}$ at $94 \mathrm{~dB}$ sound level, $1 \mathrm{kHz}$ sine wave).

Collected data have been then used to calibrate our model. Specifically, we used collected data partly as inputs to increase the accuracy of our model and as outputs to check our model against, and then calibrate it in a feedback/feedforward loop.

Thermal comfort could not be fully assessed and it indeed represents one of the limitations and recommended avenues for further research, as we will explain in more detail in Section 6. However, we were keen on assessing, to some extents, the impact on the risk of overheating due to the newly installed glazing and the southern orientation of half of the building. In this respect, the Overheating Task Force in CIBSE has recently developed a new assessment method which has been published in the Technical Memorandum No. 52 (TM52) [38]. It adopts an approach based on current European Standards [39]; however, the three criteria proposed in TM52 are more stringent than those currently used since they assess (a) the number of hours of exceedance from a threshold comfort temperature, (b) the frequency of the overheating, and (c) the severity of the overheating - respectively. TM52 assessment has been carried out from within one of the modules of IES.

\section{Data Collection and Data Analysis}

The case study building is located in the South East England and its main orientation is NE-SW. The building incorporates office activities and it is made of five storeys - one of 
which is underground. Its refurbishment has involved several elements of the building envelope; more specifically:

(1) Installation of mineral wool insulation (thickness $50 \mathrm{~mm}$; product subject to contractor's choice but compliant with BS EB 13162; thermal conductivity: 0.037 $\mathrm{W} / \mathrm{m} \mathrm{K})$;

(2) Sealing gaps and air paths;

(3) Installation of external shading systems in form of fixed louvered overhangs;

(4) Installation of suspended ceilings $(600 \times 600 \mathrm{~mm}$ tiles $12.5 \mathrm{~mm}$ thick mounted on $24 \mathrm{~mm}$ exposed grid system with $24 \mathrm{~mm}$ wide $\mathrm{T}$ section flanges equipped with $50 \mathrm{~mm}$ mineral wool wire reinforced mattress as fire barrier - compliant to BS476-20, 30/30 minutes integrity/insulation);

(5) New window frames and new glazing systems.

Building elements characteristics of both pre- and post-refurbishment cases are given in Table 1.

Table 1 - Building elements characteristics

\begin{tabular}{lccc}
\hline \multirow{2}{*}{$\begin{array}{c}\text { Elements of the building } \\
\text { envelope }\end{array}$} & $\begin{array}{c}\text { Area } \\
{\left[\mathrm{m}^{2}\right]}\end{array}$ & $\begin{array}{c}\text { Pre- } \\
\text { refurbishment }\end{array}$ & $\begin{array}{c}\text { Post- } \\
\text { refurbishment }\end{array}$ \\
\cline { 2 - 4 } & 1067.8 & 1.16 & 0.69 \\
\hline Outer walls & 488.3 & 4.66 & 1.42 \\
Windows (including frames) & 726.3 & 0.53 & 0.53 \\
Roof & 679.4 & 0.70 & 0.70 \\
Ground floor & & \\
\hline
\end{tabular}

Due to the public services carried out within the building, access for measurements and survey has been limited. However, significant data were collected, including:

- Light levels were measured in individual spaces using a lux-meter and these were inputted to the BES 
- Temperature in all accessible rooms were measured in order to compare them with those resulting from the BES and thus calibrate the model

- Heating set-points from the boiler room

- Relative humidity (RH) values were measured in all accessible rooms

- Occupancy profile of the building throughout weekdays, weekends, and Bank Holidays were acquired (Table 2)

Table 2 - Occupancy profiles for weekdays, weekends, and Bank Holidays

\begin{tabular}{lccc}
\hline \multicolumn{3}{c}{ Occupancy profiles } \\
\hline & $\begin{array}{c}\text { Monday to } \\
\text { Friday }\end{array}$ & Saturday & $\begin{array}{c}\text { Sunday and Bank } \\
\text { Holiday }\end{array}$ \\
\cline { 2 - 4 } $00: 00-7: 30$ & $0 \%$ & $0 \%$ & $0 \%$ \\
$7: 30-8: 00$ & $75 \%$ & $0 \%$ & $0 \%$ \\
$8: 00-16: 00$ & $100 \%$ & $90 \%$ & $\left.5 \%{ }^{*}\right)$ \\
$16: 00-17: 00$ & $100 \%$ & $0 \%$ & $0 \%$ \\
$17: 00-18: 00$ & $50 \%$ & $0 \%$ & $0 \%$ \\
$18: 00-0: 00$ & $0 \%$ & $0 \%$ & $0 \%$ \\
\hline${ }^{(*)}$ Estimate value for cleaning activities which take place during those days
\end{tabular}

- Specifications of the new windows and frames were accessed through the project brief and technical drawing documents. In this respect, aluminium thermal break frames have been preferred over timber and UPVC frames. For the former the reason is to be found in less maintenance required whereas for the latter the choice is due to lower embodied energy and carbon when compared to aluminium according to the BRE Green Guide cited in the report from the environmental engineers. With regard to the new glazing systems the choice has been twofold. For the NE facing windows, a double-glazing unit (DGU) which comprises Optitherm ${ }^{\circledR}$ low-e glass has been chosen. For the SW facing windows, a DGU with a Suncool@ 70/40 has been chosen in order to minimise the effect of solar thermal gain - as stated by the glass supplier in their window selection report. Additionally, the glass supplier is aware that such a 
choice for the SW facing windows impacts on the light transmittance but, according to the report prepared by them, the size of glazing and the fact that they are facing south makes the impact insignificant.

- Floor plans and layout were also acquired, and floor to ceiling heights measured to maximise the accuracy of the modelled version of the buildings (Figure 1)

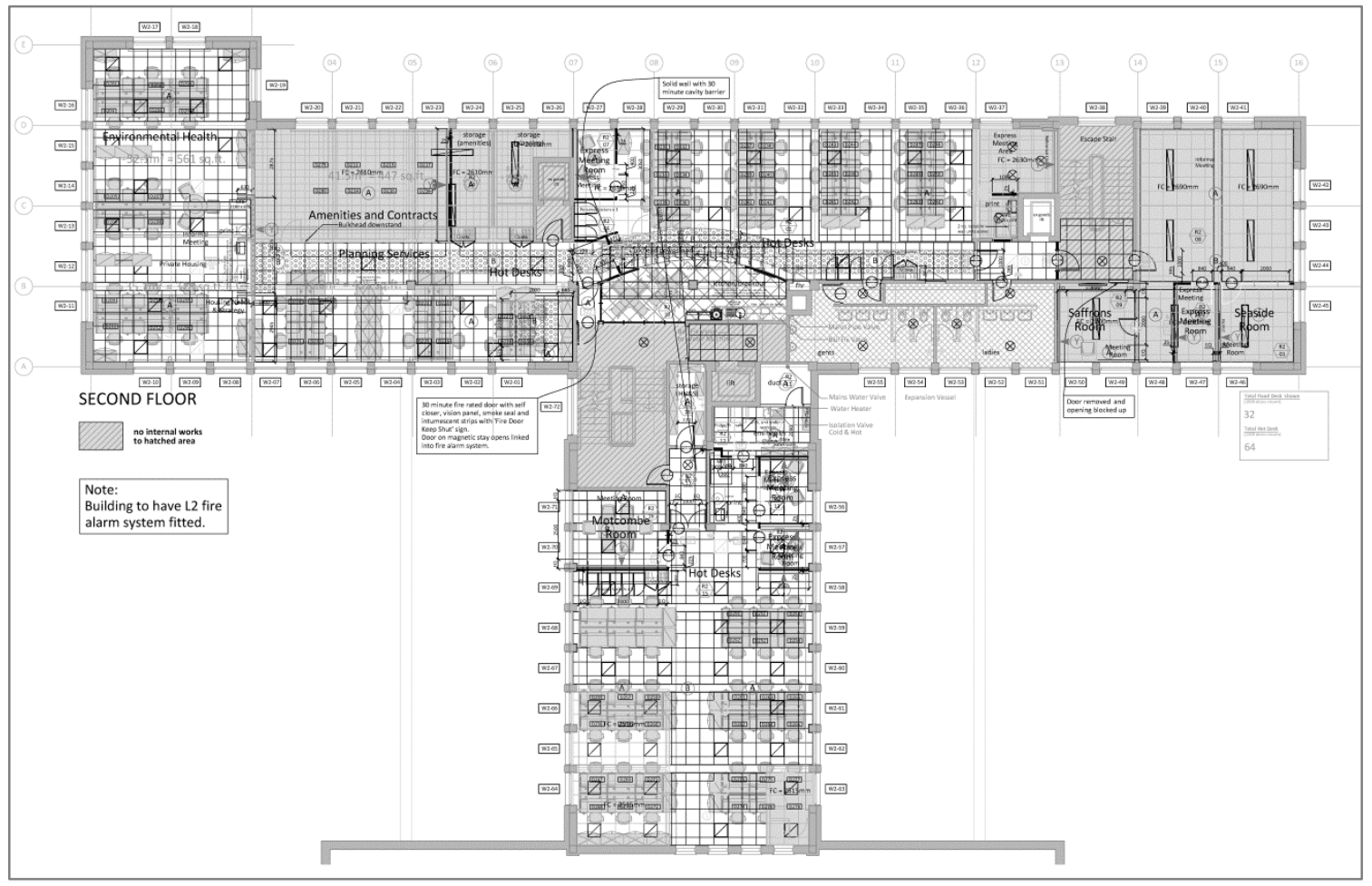

Figure 1: A sample of collected drawing documents ( $2^{\text {nd }}$ floor plan)

- Details of the windows (Figure 2) and of the shading devices (Figure 3) were also acquired, again in order to increase the accuracy of the simulation. It is worth noting that all rooms but the server room are naturally ventilated, thus requiring particular attention to the simulation of the openings, for it heavily affects thermal comfort (the $\mathrm{A} / \mathrm{C}$ server room is not considered within this study). 


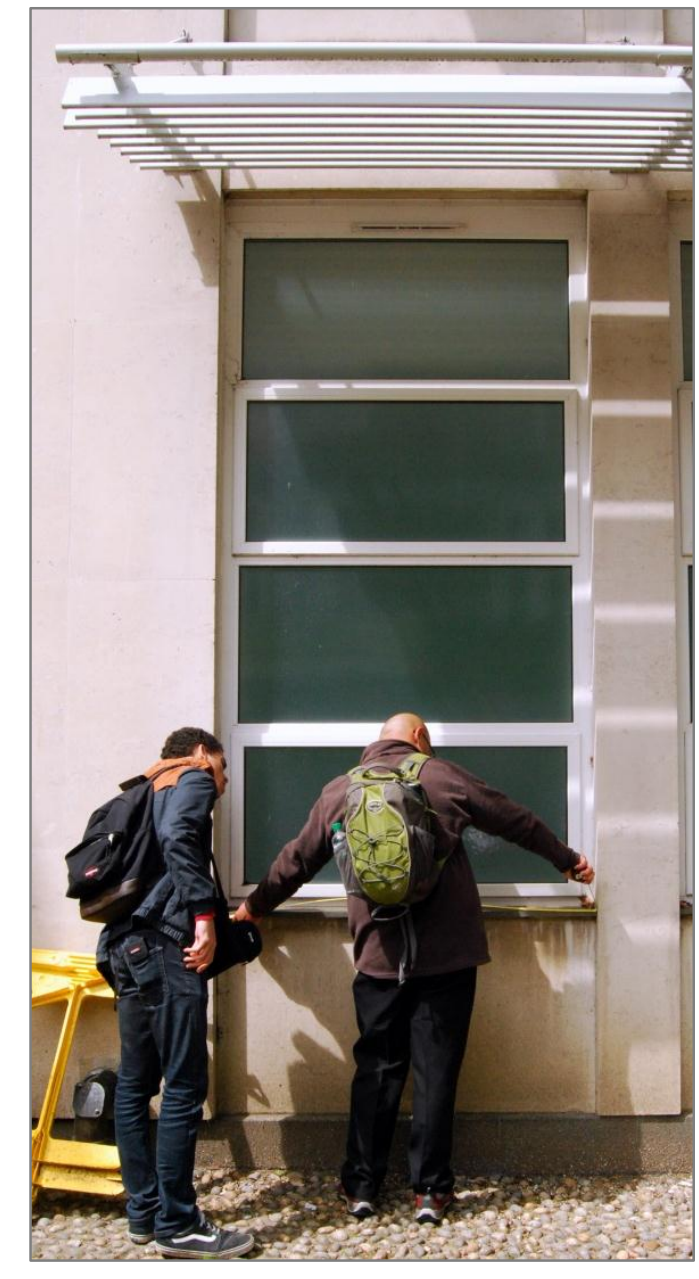

Figure 2: Detailed measurement of windows

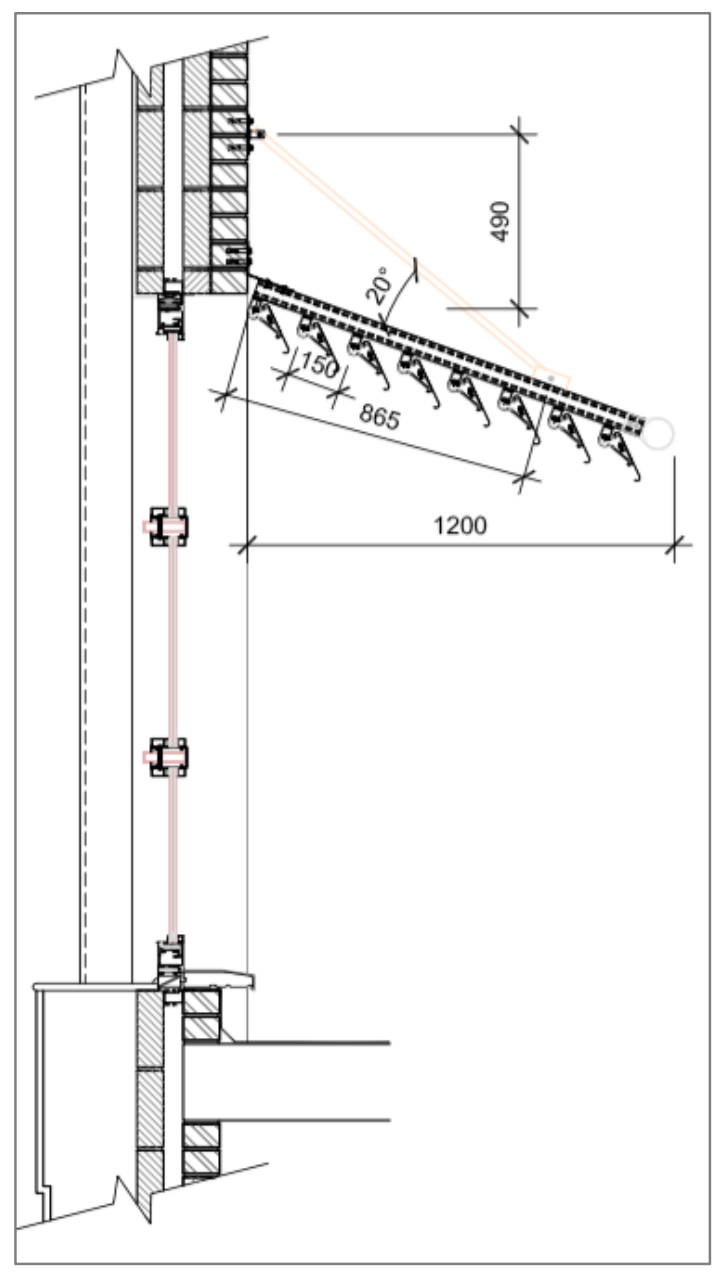

Figure 3: Details of the shading devices installed

- Finally, a survey of major shading elements (trees) surrounding the building was carried out too in order to fully replicate their presence within the simulation. In the south corner of the building, the presence of tree made the installation of the new shading devices unnecessary. For this reason, shading devices were excluded in the first two floors. It is obvious how influential the correct replication of trees within the simulation is to help achieve accurate and reliable results.

As explained before, all the data collected led to a very accurate representation of the building prior to running energy simulations. Figure 4 shows the building superimposed on its current location in Google $\mathrm{TM}^{\mathrm{TM}}$ Earth $(\mathrm{C}$. Orientations, openings, shading elements, layout of internal spaces, all are as close to their real forms and specifications as possible. We feel, in 
this respect, that more accuracy could have hardly been achieved within reasonable time and project financial limits.

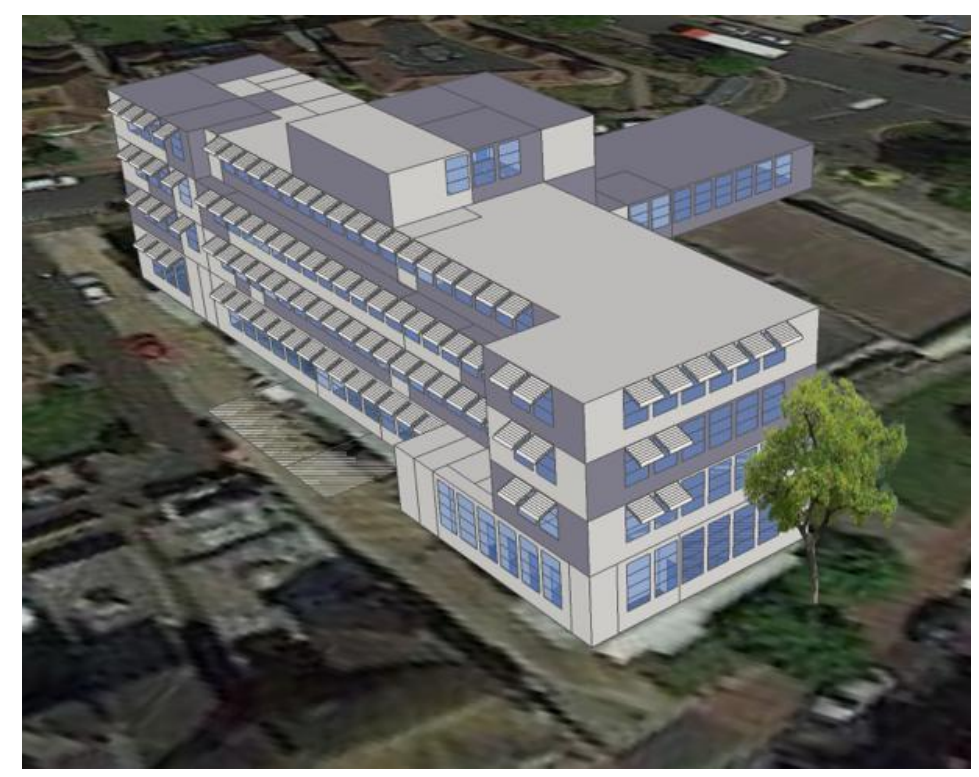

Figure 4: Building simulation model superimposed on actual site on Google ${ }^{\mathrm{TM}}$ Earth $\odot$

Subsequent rounds of simulations have been run in order to refine and adjust the model. Due to various primary data collected as an input, the adjustments mainly dealt with the windows opening threshold by users in summer months as this datum could not be collected. The accuracy of the simulations has then been checked against available evidence (Figure 5a). Values of indoor temperatures are always within a $\pm 3^{\circ} \mathrm{C}$ range to those extracted from the simulations results (Figure $5 b$ ). 
a)

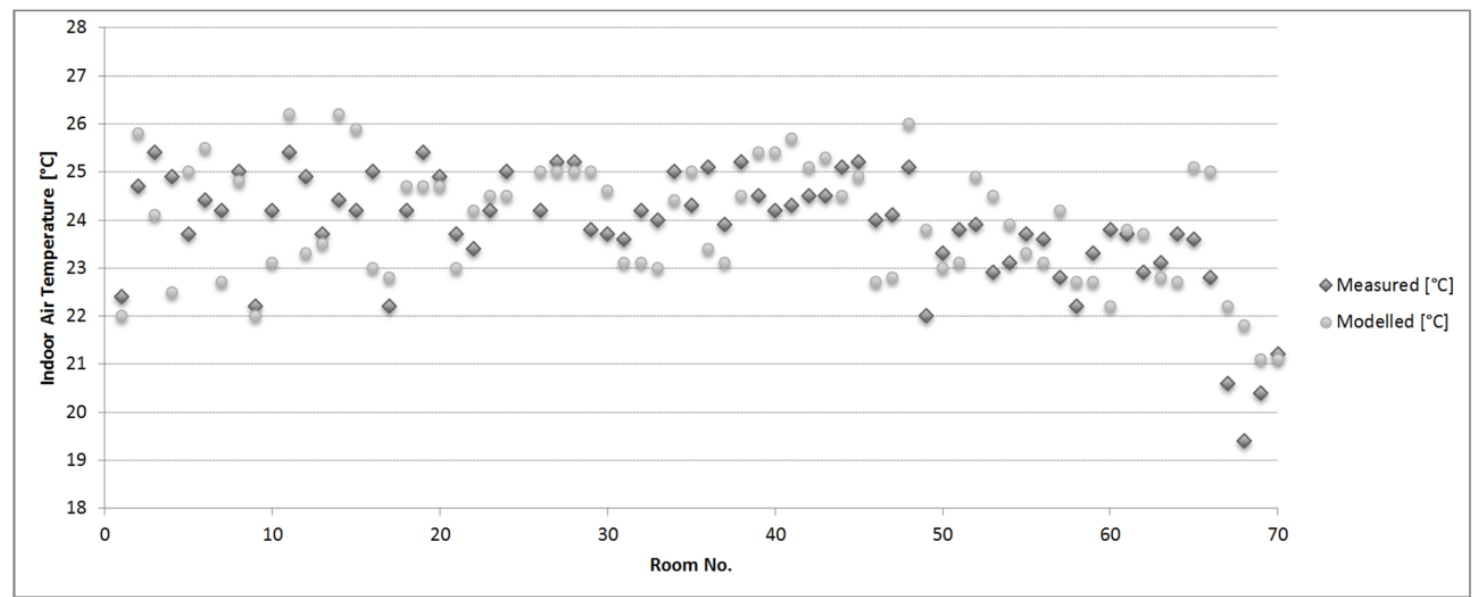

b)

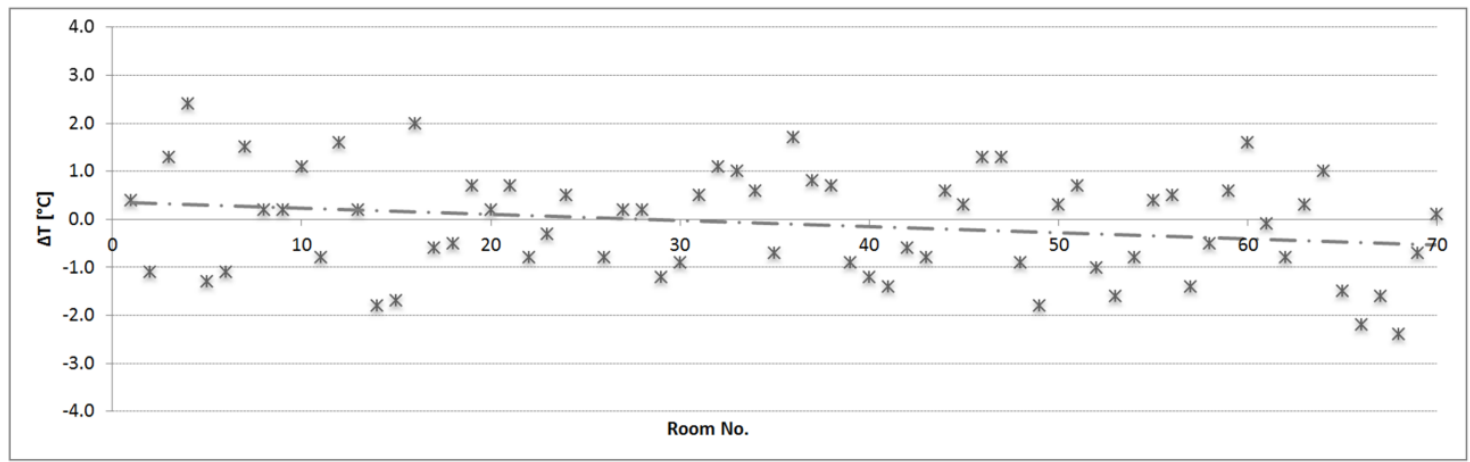

Figure 5: Relation between measured temperatures (one measurement in a day for each room) and simulation results (a), and net differences between the two (b) for each of 70 different rooms

As explained earlier, access to the building for the energy survey has been possible only in one given day. Therefore, indoor air temperature values have only been measured in that day and this does in fact represent a limitation of this study. However, given that the weather file which was used refers to London and it does not take into account the specific microclimate of the building location, the good match between measured and simulated temperatures across all accessed rooms was deemed satisfactory.

Additionally, heating loads compare significantly well with existing benchmarks for the UK office buildings [40, 41] (Figure 6). 


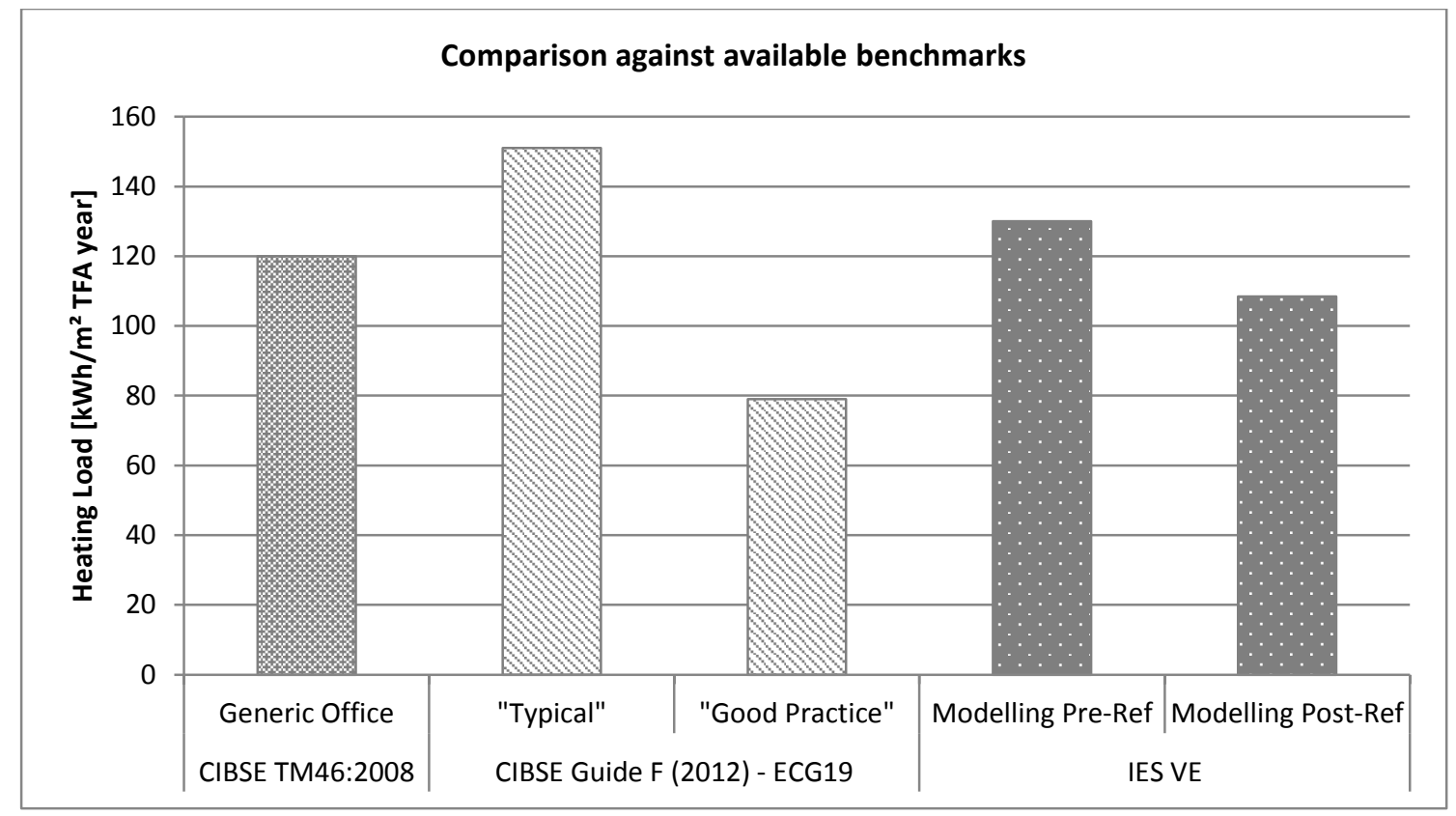

Figure 6: Comparison of modelling results against available UK energy benchmarks

More specifically, it can be seen how the refurbishment interventions have moved the loads value from that of the "Generic Office" towards the "Good Practice" area - though the "Good Practice" benchmark is still far away. Although an overall heating load reduction is observable, it is worth also presenting the results broken down into monthly values (Figure 7).

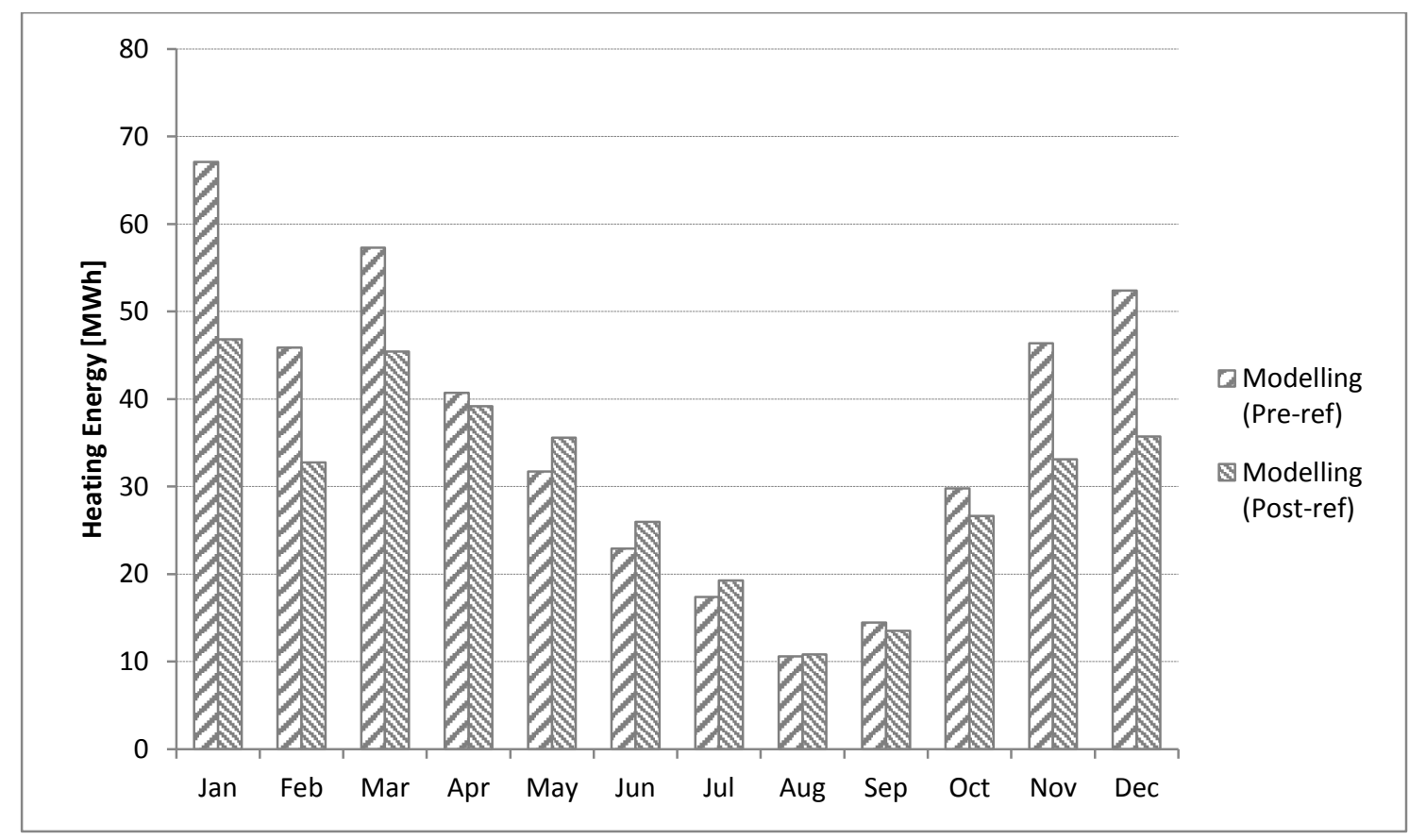

Figure 7: Monthly heating energy in both pre- and post-refurbishment scenarios 
It should be noted that the installation of DGU has actually increased the heating energy consumption in spring months. This is due to reduced solar gains, in the form of 'free' heating to the indoor spaces. This means that, during those months, more often than before the temperature drops below the heating set point, thus activating the boiler for space heating, which in turn increases energy consumption and carbon emissions.

Table 3 - Energy and Carbon values throughout a whole year for both scenarios

\begin{tabular}{|c|c|c|c|c|c|c|c|c|c|c|c|c|c|}
\hline & & & & & & & & & & & & & \\
\hline & & Jan & Feb & Mar & Apr & May & Jun & Jul & Aug & Sep & Oct & Nov & Dec \\
\hline \multirow{2}{*}{$\begin{array}{l}\text { Heating } \\
\text { energy } \\
\text { (MWh) }\end{array}$} & (Pre-ref) & 67,1 & 45,9 & 57,3 & 40,7 & 31,7 & 22,9 & 17,4 & 10,6 & 14,5 & 29,8 & 46,4 & 52,4 \\
\hline & (Post-ref) & 46,8 & 32,8 & 45,4 & 39,2 & 35,6 & 26,0 & 19,3 & 10,8 & 13,5 & 26,7 & 33,1 & 35,7 \\
\hline \multirow{2}{*}{$\begin{array}{l}\text { Lights } \\
\text { energy } \\
\text { (MWh) }\end{array}$} & (Pre-ref) & 9,0 & 8,1 & 9,0 & 8,7 & 9,0 & 8,7 & 9,0 & 9,0 & 8,7 & 9,0 & 8,7 & 9,0 \\
\hline & (Post-ref) & 11,2 & 10,1 & 11,2 & 10,9 & 11,2 & 10,9 & 11,2 & 11,2 & 10,9 & 11,2 & 10,9 & 11,2 \\
\hline \multirow{2}{*}{$\begin{array}{l}\text { HW use } \\
\text { (MWh) }\end{array}$} & (Pre-ref) & 2,9 & 2,6 & 2,9 & 2,8 & 2,9 & 2,8 & 2,9 & 2,9 & 2,8 & 2,9 & 2,8 & 2,9 \\
\hline & (Post-ref) & 2,9 & 2,6 & 2,9 & 2,8 & 2,9 & 2,8 & 2,9 & 2,9 & 2,8 & 2,9 & 2,8 & 2,9 \\
\hline \multirow{2}{*}{$\begin{array}{c}\text { Heating } \\
\text { carbon } \\
\left(\mathrm{tCO}_{2 \mathrm{e}}\right)\end{array}$} & (Pre-ref) & 13,5 & 9,2 & 11,5 & 8,2 & 6,4 & 4,6 & 3,5 & 2,1 & 2,9 & 6,0 & 9,4 & 10,6 \\
\hline & (Post-ref) & 9,4 & 6,6 & 9,2 & 7,9 & 7,2 & 5,2 & 3,9 & 2,2 & 2,7 & 5,4 & 6,7 & 7,2 \\
\hline \multirow{2}{*}{$\begin{array}{l}\text { Lights } \\
\text { carbon } \\
\left(\mathrm{tCO}_{2 \mathrm{e}}\right)\end{array}$} & (Pre-ref) & 4,0 & 3,6 & 4,0 & 3,9 & 4,0 & 3,9 & 4,0 & 4,0 & 3,9 & 4,0 & 3,9 & 4,0 \\
\hline & (Post-ref) & 5,0 & 4,5 & 5,0 & 4,8 & 5,0 & 4,8 & 5,0 & 5,0 & 4,8 & 5,0 & 4,8 & 5,0 \\
\hline \multirow{2}{*}{$\begin{array}{l}\text { HW use } \\
\left(\mathrm{tCO}_{2 \mathrm{e}}\right)\end{array}$} & (Pre-ref) & 0,6 & 0,5 & 0,6 & 0,6 & 0,6 & 0,6 & 0,6 & 0,6 & 0,6 & 0,6 & 0,6 & 0,6 \\
\hline & (Post-ref) & 0,6 & 0,5 & 0,6 & 0,6 & 0,6 & 0,6 & 0,6 & 0,6 & 0,6 & 0,6 & 0,6 & 0,6 \\
\hline
\end{tabular}

Table 3 shows another breakdown of monthly energy and carbon figures per final energy use. Guidelines and GHG conversion factors used refer to the UK context where this case study is located $[5,42,43]$. In this respect, since the building is fully naturally ventilated (apart from the server room which has been excluded in this analysis), the three most significant energy end-uses are space heating, lighting, and hot water. Yearly totals for each in both pre- and post-refurbishment scenarios are shown in Figure 8. 


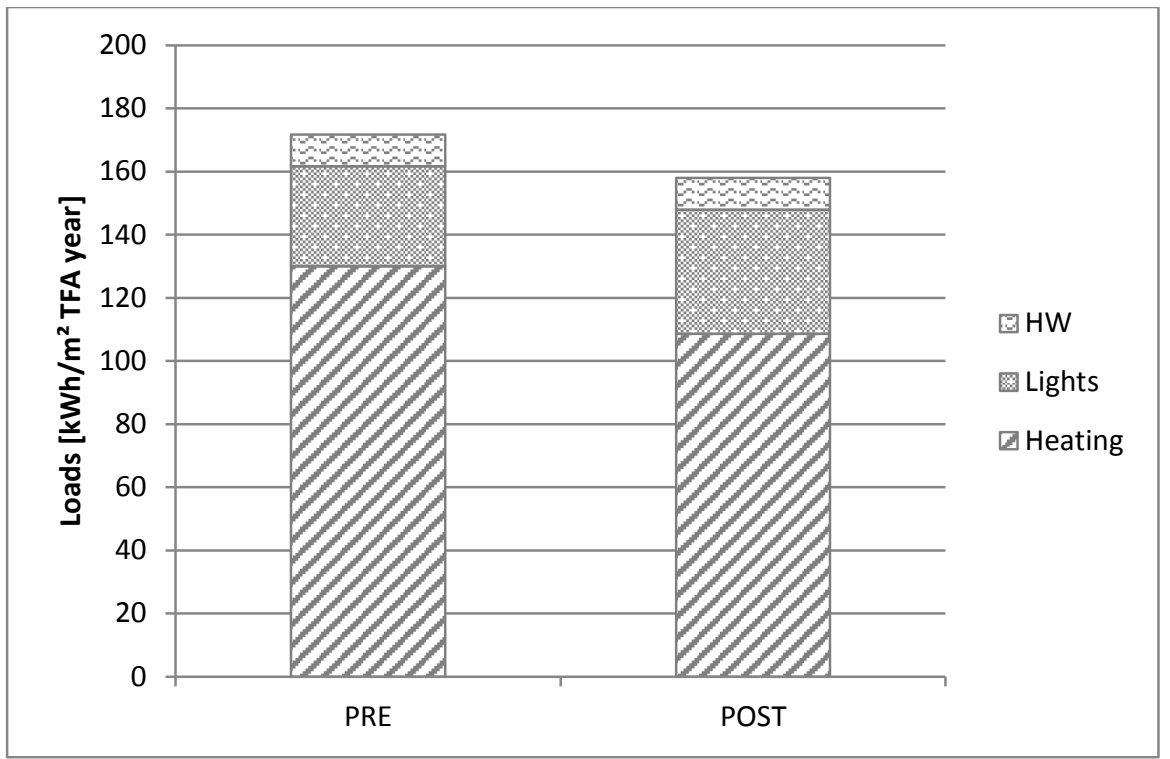

Figure 8: Breakdown of total energy into end uses for both pre- and post-refurbishment scenarios

Total natural gas energy (heating energy) dropped from 436.7 MWh/year to 364.9 $\mathrm{MWh} / \mathrm{year}$. This is one of the major changes due to improvement in performance of the building fabric as well as installation of double-glazed windows. This represents a significant reduction in space heating energy of $16.4 \%$. Consequently, $\mathrm{CO}_{2}$ emissions associated with gas consumption dropped proportionally with this figure going from $88019 \mathrm{~kg} \mathrm{CO}_{2 \mathrm{e}}$ /year to $73555 \mathrm{~kg} \mathrm{CO} 2 \mathrm{e} /$ year. Electricity consumption for lighting increased by $24 \%$ from $106 \mathrm{MWh} /$ year to $132 \mathrm{MWh} /$ Year post intervention due to the solar shading devices and the solar reflective glazing installed on the south elevation. This has a negative impact on the associated $\mathrm{CO}_{2}$ emissions which rose from $47323 \mathrm{~kg} \mathrm{CO}_{2} /$ year to $58813 \mathrm{~kg} \mathrm{CO}_{2 \mathrm{e}} /$ year post intervention. It can be observed that the guess of the glass supplier has been correct: lighting energy did increase but it is far from being insignificant. 
a)

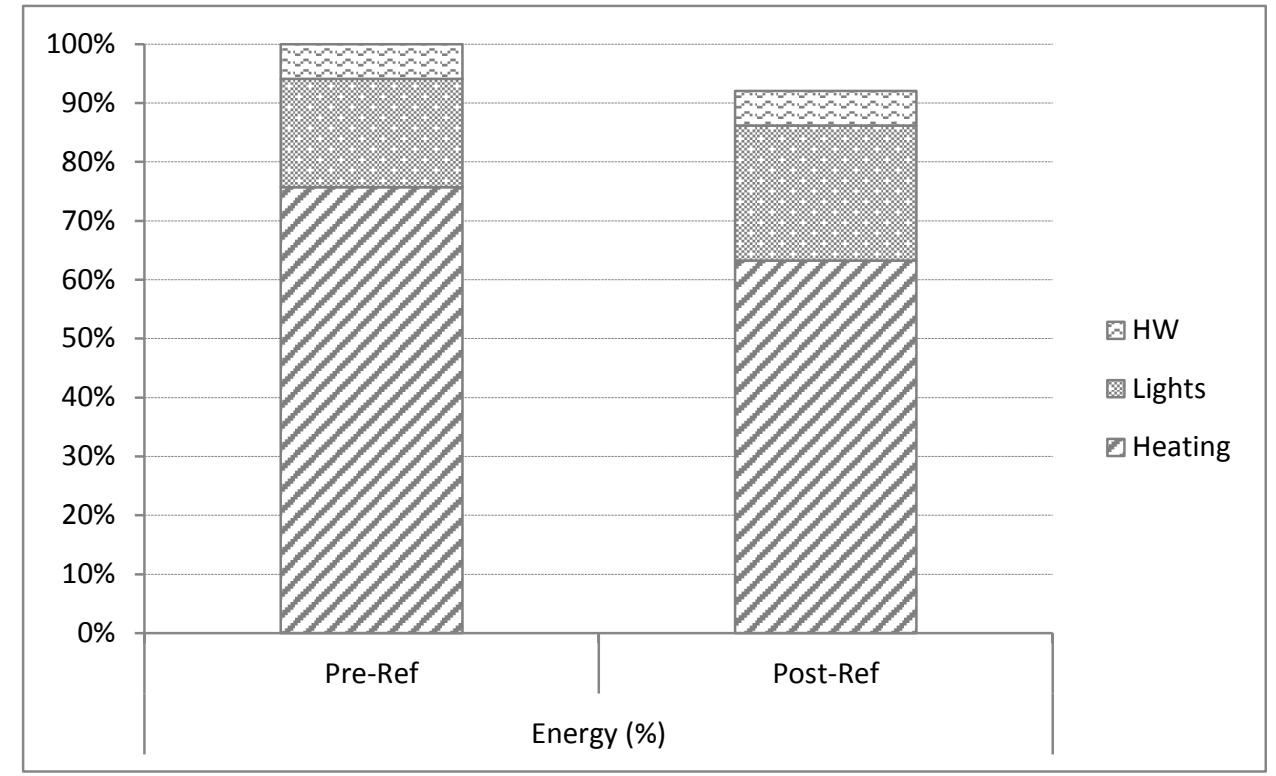

b)

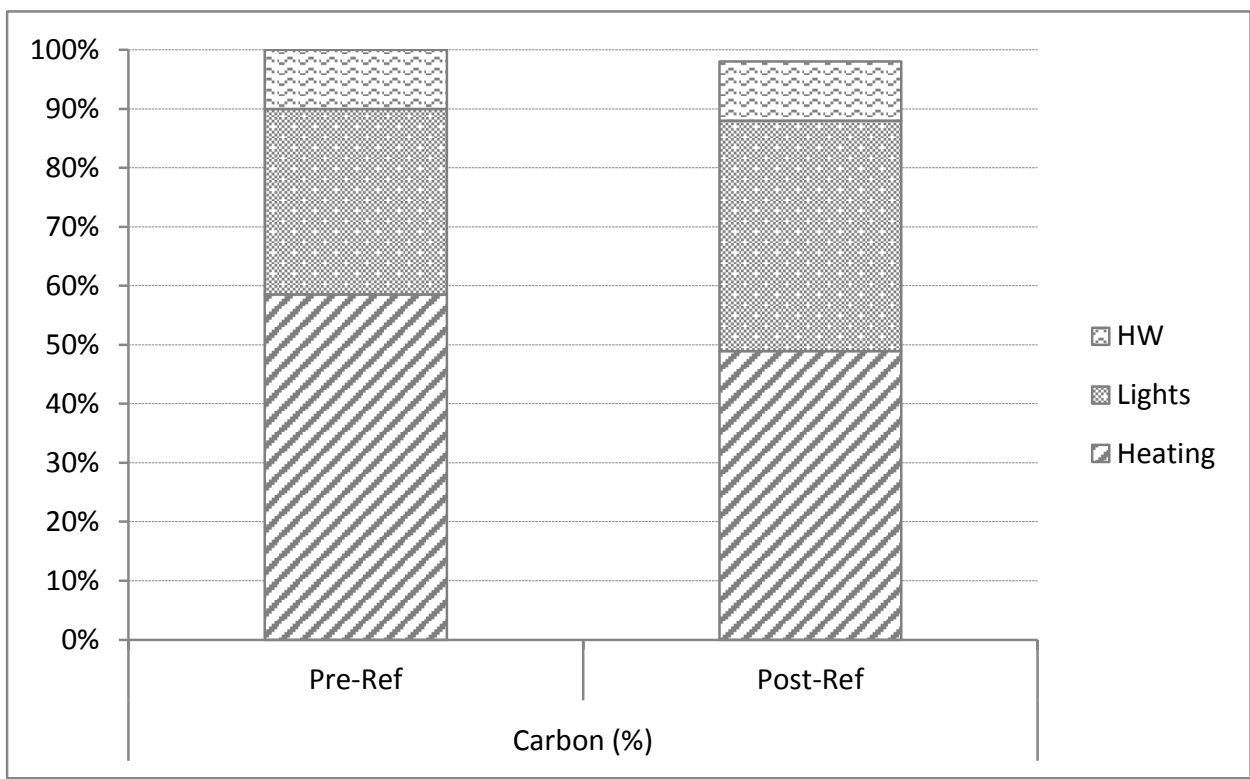

Figure 9: Yearly energy (a) and carbon (b) percentages for both pre- and post-refurbishment scenarios

Eventually Figure 9 presents cumulative yearly energy (a) and carbon (b) percentage values for the two scenarios; pre- and post-refurbishment, where in both cases $100 \%$ is the total value of the situation pre intervention.

The overheating has been assessed as per TM52 methodology as explained in Section 3. Results are presented in terms of percentage of uncomfortable rooms compared to the total 
rooms in the pre- and post-intervention scenarios. Uncomfortable rooms dropped from 21 to 7 , which represents a reduction of $67 \%$. The significant reduction echoes what energy figures indicate: the reduced solar gains that increased the space heating energy demand during spring months also decreased overheating over summer months. However, it is worth bearing in mind that the TM52 assessment is far from being comparable to a full post-occupancy survey and evaluation and therefore comfort results must be taken into account with care. Additionally, as Figure 5b indicates, in some of the rooms the indoor air temperature resulting from the BES is lower than that actual measured temperature. This means that-for those rooms - the TM52, which uses the simulated temperature for the comfort assessment, could potentially miss out uncomfortable conditions, which could instead occur in reality.

\section{Discussion of Findings}

As expected, double-glazing contributed significantly to savings in space heating energy. Indeed, the assessment of carbon and energy consumption shows a net reduction of $16 \%$. This is explained by a better insulation of the building and reduced losses from the buildings' fabric, whose location near the sea implies less temperature variations and (very) limited severe weather conditions during a typical calendar year.

However, this is just one side of the story. Operational energy figures need to be assessed holistically, and therefore focusing just on the heating reduction would be misleading. In fact, interventions in the building envelope have also significantly increased need for artificial lighting hence an increase in electricity consumption. When both results are taken into account, operational energy reduction is less significant (Figure 10) totalling a less remarkable $8 \%$. This finding is in line with some results from the literature [30], where researchers have found that the upgrade of original windows with low-e DGUs did not significantly reduce the operational energy consumption in the buildings they modelled. 
From the carbon point of view things just do not actually improve. In fact, they worsen as the total reduction as a result of the interventions is just $2 \%$. This is due to the higher GHG conversion factor or carbon density $\left(\mathrm{kg} \mathrm{CO}_{2} \mathrm{e} / \mathrm{kWh}\right)$ that electricity has compared to natural gas. From a carbon (environmental) perspective then, the significant increase in lighting, due to the combined choice of solar control DGU and shading devices, almost totally outweighs the benefit of the whole refurbishment. This result is extremely important. More specifically, it highlights that close attention is to be paid to avoid moving environmental burdens from one energy end use to another which, like in this case, has a higher environmental impacts due to the specific energy mix, i.e. electricity vs. natural gas. Environmentally speaking, it would be extremely interesting to see what the life cycle GHG impacts would be like, when embodied energy related to pre- and post-occupancy stages of the building is taken into account.

\section{Conclusions, Limitations and Further Research}

Improvements to the building envelopes are believed to be beneficial and this was shown in the literature review presented in Section 2. However, the results from the building case studied in this research indicated otherwise. The energy reduction achieved is not as significant as suggested by the literature and when carbon reduction is taken into account improvements become extremely marginal due to different energy mix and conversion factors specific to the geographical context of the study. More specifically, additional insulation, high performance DGUs, and shading devices failed, to some extent, to deliver the "sustainable" or "environmentally friendly" refurbishment that was initially intended. For instance, operational carbon reduction only totalled an insignificant $2 \%$.

More attention needs therefore to be paid when approaching refurbishment projects. This can include a full pre-refurbishment survey, as suggested by different professional bodies $[18,44,45]$. For instance, within the RIBA's Plan of Work there are - at each and 
every stage - measures aimed at reducing the performance gap between what was planned and what is actually achieved [45]. Similarly, CIBSE's Technical Memorandum No. 53 defines as 'essential' to undertake a full survey of the existing building prior to commencing any refurbishment work. Such a survey should chiefly serve the purpose of investigating the viability of the intended refurbishment and address potential alternatives - should there be any need for it. Table 4 highlights the main elements from the two aforementioned documents that the case study addressed in this article would have greatly benefitted from if pre-refurbishment measures were taken into account more proactively.

Table 4: Essential elements from RIBA (2014) and CIBSE (2013) that would have greatly helped inform the refurbishment considered in this article

\section{RIBA Plan of Work (2014)}

Stage 1: definition of project outcomes, sustainability aspirations, and feasibility necessity to undertake surveys and monitoring Stage 2: definition of maintenance and operational strategy, third party consultancy, $\mathrm{R} \& \mathrm{D}$ aspects

Stage 3: review and update the sustainability and operational strategy, finalise $R \& D$ aspects Stage 4: update of design-stage carbon and energy declaration, draft of non-technical user guide

Stage 5: completeness check of the user guide Stage 7: post-occupancy evaluation, review of project performance, project outcomes, and $\mathrm{R} \& \mathrm{D}$ aspects, observation of the building in use and "assistance with fine tuning guidance for occupants".

\section{CIBSE TM53 (2013)}

Depending on the scope and extent of the refurbishment work, the survey should cover as much as possible of the following: a) present building conditions (internal layout, fabric condition, current energy performance, current occupancy profile and heat gains); b) building history (previous refurbishments, original fabrics, previous building performance failures and corresponding reasons [thermal/ visual/ acoustic/ air quality]);

c) building location (microclimate [topography, vegetation], orientation and exposure to solar gains, to pollutants, and to environmental hazards [flooding, storms, heat waves].

Quite evidently, a few of the core elements presented in Table 4 have not been sufficiently addressed in the refurbishment project studied in this research. If the aim was to deliver a low-carbon refurbishment a clear definition of the sustainability aspirations, and an execution, ex ante, of the operations that this research has done, ex post, would have shown little likelihood of achieving successful outcomes given the choices that have eventually been made. Moreover, further and careful considerations related to the building orientation, its topography, and the exposure to solar gains would probably have led to different choices in 
the glazing types adopted. Very similar claims can be done also in relation to occupancy profiles, and internal gains - although these influenced the outcome of the refurbishment to a lesser extent.

The main recommendation here is that a thorough full-scale study should be done prior to each and every refurbishment project, regardless of how well agreed-upon the planned interventions are. In fact, building location and orientation, site constraints, and occupancy patterns - just to name a few - are all context specific features that may well play a determinant role in making a conventional refurbishment a success or otherwise cause it to fail. This will further prove that our established understandings of conventional measures for energy interventions might not always be applicable and cannot be rolled out regardless of the contextual conditions.

In addition to this, there seems to have been very little engagement with building users despite the fact that the main purpose of an office building is to provide a healthy, comfortable and productive environment for its occupants [46]. If this problem is contemplated over in a more comprehensive context and occupants, as the ultimate users of the space, are collectively consulted both prior and during the project, many problems can be prevented and those few which may still persist, can be addressed and overcome in a collective manner through collaborative working processes. Moreover, more in-time use of rather proven techniques such as consultation, simulation, test scenarios, design and technological solutions alternatives not only can help improve the user satisfaction but also raise their awareness and enhance their space use behaviour; what can be very much nurtured through a mutual two-way communication channel where the end-users can be sure that they are heard, listened to and their opinions, needs, wants and preferences have all been taken into account, and deployed for the collective good of the work place. 
In this respect the lack of consideration of building's users represent the main limitation of our work. This was partially due to limited time and resources available in the course of this project and to some bigger extent because access to the occupants was restricted/denied by both the clients' and project manager's concerns around the outcome of our study as it might not conform to the strategic goalposts of the project; what introduced some restriction on direct access to the occupants as the space end-users. More specifically, a post occupancy survey was designed and emailed to the project manager with an aim to be circulated amongst the building's users. Unfortunately, they have never been given our questionnaire and their views and responses had therefore to be neglected in our work. Another limitation, partially linked to the previous one, is related to the restricted access to the premises. As mentioned in the paper, the building survey had to be completed within one single day and, for such a reason, we could not collect indoor environmental data over a longer period of time, which would have strengthened the validation of our simulated results. Nevertheless, existing studies often rely solely on simulation to assess pre- and postrefurbishment energy figures. We therefore believe that, despite it being limited, our in-situ measurements add values to the sole use of building simulation tools.

Given the main limitation of our work, adaptive comfort assessment based on the newest research insights [47] and post-occupancy surveys surely represent an interesting direction for further research. Additionally, in relation to the planning, design, management, and delivery of the refurbishment projects, users' expectations, satisfaction and engagement are all worthwhile avenues for future investigations.

\section{Acknowledgment}

The authors would like to thank the local authority who has kindly provided all the relevant documents pertaining to the energy refurbishment as well as access to their building for this 
research. Mr. Rémi Soulisse from Université Paris Ouest Nanterre La Défense IUT Ville

d'Avray on Erasmus exchange visit at University of Brighton helped with data collection for

this study.

\section{References}

[1] A. Horvath, Construction Materials and the Environment, Annual Review of Environment and Resources, 29 (1) (2004) 181-204.

[2] M.K. Dixit, J.L. Fernández-Solís, S. Lavy, C.H. Culp, Identification of parameters for embodied energy measurement: A literature review, Energy and Buildings, 42 (8) (2010) 1238-1247.

[3] G. Assefa, M. Glaumann, T. Malmqvist, B. Kindembe, M. Hult, U. Myhr, O. Eriksson, Environmental assessment of building properties-Where natural and social sciences meet: The case of EcoEffect, Building and Environment, 42 (3) (2007) 1458-1464.

[4] L. Pérez-Lombard, J. Ortiz, C. Pout, A review on buildings energy consumption information, Energy and Buildings, 40 (3) (2008) 394-398.

[5] DECC, Digest of United Kingdom Energy Statistics 2013, in, Department of Energy \& Climate Change, London, 2013.

[6] D. Bouchlaghem, Architectural Engineering and Design Management: Sustainability Themed Issue, Architectural Engineering and Design Management, 8 (1) (2012) 3-5.

[7] K. Steemers, Energy and the city: density, buildings and transport, Energy and Buildings, 35 (1) (2003) 3-14.

[8] J. Ravetz, State of the stock-What do we know about existing buildings and their future prospects?, Energy Policy, 36 (12) (2008) 4462-4470.

[9] Carbon-Trust, Building the future, today. Transforming the economic and carbon performance of the buildings we work in., in, 2009.

[10] CIBSE, BSRIA, Refurbishment for Improved Energy Efficiency: An Overview, in: CIBSE (Ed.) Knowledge Series 12, 2007, pp. 48.

[11] ODPM, Age of Commercial and Insustrial Stock: Local Authority Level 2004, in:

Office-of-the-Deputy-Prime-Minister (Ed.), ODPM Publications - Crown copyright 2005, London, 2005, pp. 24.

[12] S. Roberts, Altering existing buildings in the UK, Energy Policy, 36 (12) (2008) 4482 4486.

[13] L. Thomas, Evaluating design strategies, performance and occupant satisfaction: a low carbon office refurbishment, Building Research \& Information: The International Journal of Research, Development and Demonstration, 38 (6) (2010) 610-624.

[14] I. Blom, L. Itard, A. Meijer, Environmental impact of dwellings in use: Maintenance of facade components, Building and Environment, 45 (11) (2010).

[15] F. Ardente, M. Beccali, M. Cellura, M. Mistretta, Energy and environmental benefits in public buildings as a result of retrofit actions, Renewable and Sustainable Energy Reviews, 15 (1) (2011) 460-470.

[16] M.A. Shameri, M.A. Alghoul, K. Sopian, M.F.M. Zain, O. Elayeb, Perspectives of double skin facade systems in buildings and energy saving, Renewable \& Sustainable Energy Reviews, 15 (3) (2011) 1468-1475.

[17] Carbon-Trust, Low Carbon Refurbishment of Buildings. A guide to achieving carbon savings from refurbishment of non-domestic buildings., in, 2008. 
[18] CIBSE, CIBSE TM 53: 2013 - Refurbishment of non-domestic buildings, in, Great Britain, 2013.

[19] F. Stevenson, Reducing energy demand through retrofitting buildings, Building Research \& Information, 41 (5) (2013) 605-608.

[20] EU, Directive 2010/31/EU of the European Parliament and of the Council of 19 May 2010 on the energy performance of buildings (recast), in, Official Journal of the European Union, 2010, pp. L153/113-L153/135.

[21] N.W.O. Brown, S. Olsson, T. Malmqvist, Embodied greenhouse gas emissions from refurbishment of residential building stock to achieve a 50\% operational energy reduction, Building and Environment, 79 (0) (2014) 46-56.

[22] LCICG, Low Carbon Innovation Coordination Group. Non-Domestic Buildings Summary Report, in, Departiment of Energy and Climate Change \& Carbon Trust, UK, 2012. [23] DECC, 2012 UK Greenhouse Gas Emissions, Final Figures, in, Department of Energy \& Climate Change, London, 2014.

[24] E. Dascalaki, M. Santamouris, On the potential of retrofitting scenarios for offices, Building and Environment, 37 (6) (2002) 557-567.

[25] B. Güçyeter, H.M. Günaydın, Optimization of an envelope retrofit strategy for an existing office building, Energy and Buildings, 55 (0) (2012) 647-659.

[26] M. Santamouris, E. Dascalaki, Passive retrofitting of office buildings to improve their energy performance and indoor environment: the OFFICE project, Building and Environment, 37 (6) (2002) 575-578.

[27] I.L. Wong, P.C. Eames, S. Perera, Energy simulations of a transparent-insulated office façade retrofit in London, UK, Smart and Sustainable Built Environment, 1 (3) (2012) 253276.

[28] Q. Jin, M. Overend, Facade Renovation for a Public Building Based on a Whole-Life Value Approach, in: Proceedings of Building Simulation and Optimisation Conference 2012, Loughborough, 2012, pp. 378-385.

[29] D.P. Jenkins, H. Singh, P.C. Eames, Interventions for large-scale carbon emission reductions in future UK offices, Energy and Buildings, 41 (12) (2009) 1374-1380.

[30] U. Iyer-Raniga, J.P.C. Wong, Evaluation of whole life cycle assessment for heritage buildings in Australia, Building and Environment, 47 (2012).

[31] I. Benbasat, D.K. Goldstein, M. Mead, The case research strategy in studies of information systems, MIS quarterly, 11 (3) (1987) 369-386.

[32] R.E. Stake, The art of case study research, Sage, Thousand Oaks, CA, 1995.

[33] R.K. Yin, Case study research: Design and methods, 4th ed., Sage publications, Thousands Oak, CA, 2009.

[34] E.W.K. Tsang, Case studies and generalization in information systems research: A critical realist perspective, The Journal of Strategic Information Systems, 23 (2) (2014) 174186.

[35] C.R. Benz, I. Newman, Mixed methods research: Exploring the interactive continuum, SIU Press, 2008.

[36] M. Beverland, A. Lindgreen, What makes a good case study? A positivist review of qualitative case research published in Industrial Marketing Management, 1971-2006, Industrial Marketing Management, 39 (1) (2010) 56-63.

[37] IES, Building Energy and Environmental Modelling; Checklist for Choosing BEEM Software. ApacheSim., in, 2009.

[38] CIBSE, TM 52: 2013 - The limits of thermal comfort: avoiding overheating in European buildings, in, Great Britain, 2013. 
[39] BSI, BS EN 15251:2007 - Indoor environmental input parameters for design and assessment of energy performance of buildings addressing indoor air quality, thermal environment, lighting and acoustics., in, 2007.

[40] CIBSE, CIBSE TM 46: 2008 - Energy benchmarks., in, Great Britain, 2008.

[41] EEBPP, Energy use in offices, in: Energy Consumption Guide 19, (London: Energy Efficiency Best Practice Programme), 2000.

[42] DECC, Energy Consumption in the United Kingdom (ECUK) - User Guide, in, Department of Energy \& Climate Change, London, 2013.

[43] N. Hill, H. Walker, J. Beevor, K. James, Guidelines to Defra / DECC's GHG

Conversion Factors for Company Reporting: Methodology Paper for Emission Factors, in, DEFRA, Department for Environment, Food and Rural Affairs (DEFRA) and Department of Energy and Climate Change (DECC). London, 2011.

[44] ACE, ACE Agreements. Association for Consultancy and Engineers., in, London, UK, 2009.

[45] RIBA, Plan of Work (digital online version). Royal Institute of British Architects, in, London, 2014.

[46] S. Burton, Energy Efficient Office Refurbishment, James \& James (Science Publisher) Ltd, London, UK, 2001.

[47] M.A. Humphreys, H.B. Rijal, J.F. Nicol, Updating the adaptive relation between climate and comfort indoors; new insights and an extended database, Building and Environment, 63 (0) (2013) 40-55. 